\title{
The hot foot syndrome: Evans' sign and the old way
}

\author{
RJ Evans MD MRSC(Eng) CRCSC, C Peter N Watson MD FRCPC
}

\author{
RJ Evans, C Peter N Watson. The hot foot syndrome: Evans' sign \\ and the old way. Pain Res Manage 2012;17(1):31-34.
}

BACKGROUND: Pelvic cancers such as cancer of the cervix can spread locally to involve adjacent structures such as the lumbosacral plexus and the sympathetic chain. When this happens the prognosis is usually poor. An early suspicion of recurrence may result in investigation leading to earlier and better treatment. A physical sign that may be an early and only sign of recurrence is described.

OBJECTIVE: To report the late Dr Ramon Evans' unpublished case series of the hot foot syndrome due to (mostly malignant) retroperitoneal disease. This unique contribution is an opportunity to pay tribute to a man who was a meticulous recorder of the patient narrative and practitioner of a detailed and comprehensive physical examination.

METHODS: A longitudinal, observational, retrospective, descriptive study is reported. Data were collected from a convenience sample of 86 patients, 75 of whom had retroperitoneal cancer and 11 of whom were diagnosed with other conditions in that area. Patients referred to the Smythe Pain Clinic were seen at both the Princess Margaret Hospital and Toronto General Hospital in Toronto, Ontario, in the 1970s. They were referred with intractable pain in the leg or back and often a history of a treated abdominal or pelvic cancer in the previous months or years. Baseline demographic data were collected including age, sex, diagnosis, pain location, characteristics and severity, physical findings, investigations and mortality.

RESULTS: The 86 subjects comprised 27 men and 59 women. Carcinoma of the cervix was the most common tumour. Most had a presenting complaint of leg pain. Neurological physical signs were demonstrated in the lower extremities in 44\%; however, $56 \%$ (48 patients) had only an ipsilateral, warm, dry 'hot foot' due to sympathetic deafferentation. The prognosis for the underlying illness was poor for the malignant group.

DISCUSSION: Sympathetic interruption by cancer is well known in apical lung cancer as the tumour spreads upwards to involve the inferior brachial plexus. An analogous situation occurs as cancers, such as that of the cervix, spread laterally to invade the lumbosacral plexus and sympathetic chain. Signs of sympathetic deafferentation (the 'hot foot') may be the earliest and only sign in this situation. This sign may be missed unless it is anticipated and a thorough physical examination carried out.

CONCLUSION: Evans' sign is important because it may be an early and solitary sign of retroperitoneal recurrence of pelvic (cervix, rectum, bladder, ovary and prostate) cancers. Recognition of this finding when intractable pain in the back and leg occurs with a history of this type of cancer could lead to earlier and more successful treatment.

\section{Key Words: Evan's sign; Hot foot syndrome; Retroperitoneal cancer}

There were some that got the message in the old way,

And the flashes in the darkness spoke of you.

Ronald Hopwood: The Old Way

and

Fortune favours the prepared mind

Louis Pasteur

$\mathrm{T}$ he present article is unusual in that the primary author, Ramon Evans (Figure 1), is deceased (1932 to 2007) (1). Dr Evans was a pioneer in pain treatment in Canada, founder of the Irene Eleanor Smythe (wife of Conn Smythe) Pain Clinic at Toronto General Hospital and founding member and a past president of the Canadian Pain Society. Dr C Peter N Watson was given his published articles, presentations and manuscripts by his wife, Anne. On reviewing these,

\section{Le syndrome des pieds brûlants : le signe d'Evans et la méthode ancienne}

HISTORIQUE : Les cancers pelviens, tels que le cancer du col de l'utérus, peuvent se propager aux structures adjacentes, telles que le plexus lombosacré et la chaîne sympathique. En général, le pronostic est alors mauvais. Une présomption précoce de récurrence peut susciter des explorations qui assureront un meilleur traitement, plus rapide. Un signe physique, qui pourrait bien être un signe précoce et unique, est décrit.

OBJECTIF : Rendre compte de la série de cas non publiée de feu le docteur Ramon Evans sur le syndrome des pieds brûlants causé par une maladie rétropéritonéale (surtout maligne). Cet apport unique est une occasion de rendre hommage à un homme qui consignait méticuleusement les doléances du patient et qui procédait à un examen physique détaillé et complet.

MÉTHODOLOGIE : Une étude d'observation longitudinale, rétrospective et descriptive est exposée. Les données provenaient d'un échantill on de commodité de 86 patients, dont 75 avaient un cancer rétropéritonéal et 11, d'autres maladies dans cette région du corps. Les patients aiguillés vers la clinique de la douleur Smythe ont été vus au Princess Margaret Hospital ou au Toronto General Hospital de Toronto, en Ontario, pendant les années 1970. Ils ont été orientés en raison de douleurs réfractaires d'une jambe ou du dos et avaient souvent été traités pour un cancer abdominal ou pelvien au cours des années ou des mois précédents. Les données démographiques de départ ont été colligées, y compris l'âge, le sexe, le diagnostic, le foyer de la douleur, les caractéristiques et la gravité, les observations physiques, les explorations et la mortalité.

RÉSULTATS : Les 86 sujets comprenaient 27 hommes et 59 femmes. Le carcinome du col de l'utérus était la tumeur la plus courante. À la présentation, la plupart se plaignaient de douleurs aux jambes. Les signes physiques neurologiques étaient démontrés dans les membres inférieurs chez $44 \%$ des patients, mais $56 \%$ (48 patients) n'avaient qu'un « pied brûlant » ipsilatéral sec et chaud au toucher, causé par une désafférentation sympathique. Le pronostic de la maladie sousjacente était mauvais dans le groupe atteint d'une maladie maligne.

EXPOSÉ : L'interruption sympathique par le cancer est bien connue en cas de cancer apical des poumons lorsque la tumeur se propage vers le haut pour toucher le plexus brachial inférieur. Une situation analogue se produit lorsque les cancers, tels que celui du col de l'utérus, se répandent latéralement pour envahir le plexus lombosacré et la chaîne sympathique. Le signe de désafférentation sympathique (le «pied brûlant») est peut-être le premier et le seul à indiquer cette situation. On peut le négliger, à moins de le prévoir et de procéder à un examen physique approfondi.

CONCLUSION : Le signe d'Evans est important, car il pourrait bien constituer un signe précoce et solitaire de récurrence rétropéritonéale de cancers pelviens (col de l'utérus, rectum, vessie et prostate). Une telle constatation en présence de douleurs réfractaires du dos et de la jambe, accompagnées d'antécédents de ce type de cancer, pourrait permettre d'amorcer un traitement plus rapidement et avec plus de succès.

an unpublished complete manuscript was discovered of an original and important observation: the hot foot syndrome. The establishment of precedence for this finding goes back to an article and letter published in the British Medical Journal in 1978. The article was a case report of unilateral lumbar sympathectomy due to retroperitoneal tumour by RC Brown (2). This paper was followed by a letter from ICM Paterson entitled "The Hot Foot Syndrome" (3). He referred to Dr Evans as having presented a number of such cases at medical meetings and to Dr Paterson's own and subsequent accumulation of six cases. In the opinion of Dr Paterson, the hot foot sign was "a very valuable indicator which may precede all other evidence of tumour recurrence”.

The purpose of the present article is not only to report Dr Evans' case series of this unique contribution, but also to pay tribute to a man who was a meticulous recorder of the patient narrative and practitioner 


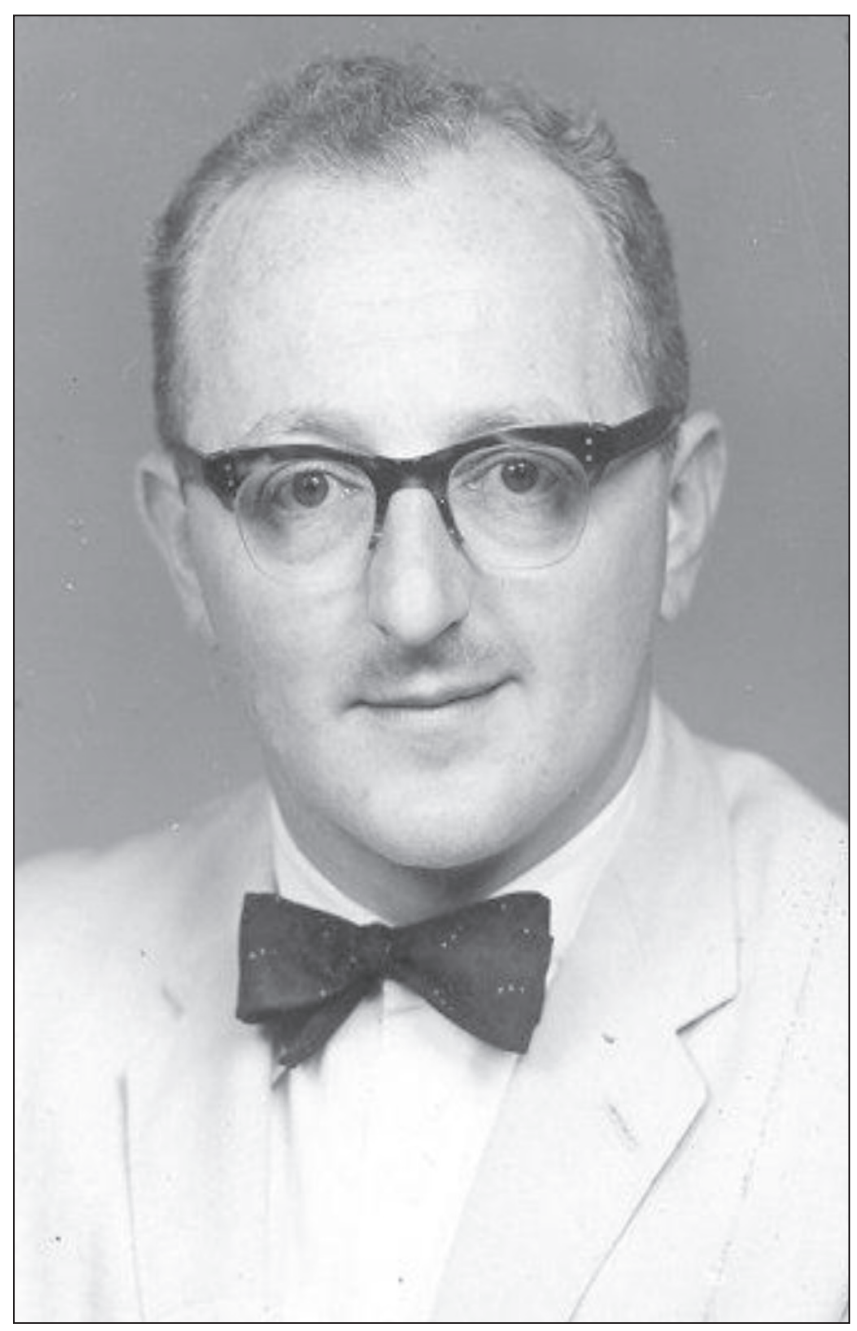

Figure 1) Dr Ramon Evans (1932-2007) in 1964 on arrival in Canada

of a detailed and comprehensive physical examination in an era when investigation techniques antedated computed tomography (CT) and magnetic resonance imaging (MRI). For my (Dr C Peter N Watson) part, he was one of the best clinical teachers I ever had. He was a general surgeon trained in the British tradition, with extensive and broad clinical experience from the early years of medical education utilizing observational data in the old way of Osler, Sydenham and a legion of others back to Hippocrates. Because of this, he not only found clinical signs, but because of his 'prepared mind' he also knew the significance of them as he knew the anatomy and natural history of diseases such as various cancers. Dr Evans accumulated these cases of neuropathic pain with sympathetic deafferentation in the lower limb, which he called the "hot foot syndrome", over some years, teaching his students about this sign and presenting these data at scientific meetings.

\section{ANATOMY OF THE RETROPERITONEAL SPACE}

The retroperitoneal space extends from the diaphragm above to the pelvic diaphragm below. This area is bounded posteriorly by the bodies of the lumbar vertebrae, sacrum and the attached musculature. Anteriorly, the posterior parietal peritoneum binds the ascending and descending colon, pancreas and rectum to the posterior abdominal wall. The major structures in this potential space are the kidneys, ureters, adrenals, pancreas, systemic vasculature, veins of the portal system, lymphatics, nerves, the lumbosacral plexus and, of importance to the present paper, the sympathetic chain and ganglia. Because the retroperitoneal space is distensible, tumours may become very large before they are diagnosed, and the most common presenting symptoms, which can be late in occurring, are abdominal pain, backache, and pain and swelling of the ipsilateral leg. The physical signs may include abdominal masses, edema of the legs and neurological deficits. Current imaging techniques include CT and MRI, but when most of the present case series was accumulated, the predominant techniques were lymphography, intravenous pyelography and venography. A biopsy establishes the diagnosis.

\section{METHODS}

The present longitudinal, observational, retrospective, descriptive study was carried out over a number of years in the 1970s. Data were collected from a convenience sample of 86 patients, 75 of whom had retroperitoneal cancer and 11 of whom were diagnosed with other conditions in that area. They were referred to the Smythe Pain Clinic and seen at the Princess Margaret Hospital and Toronto General Hospital in Toronto, Ontario. Patients were referred with intractable pain in the abdomen and/or back and/or leg. There was often a history of a treated abdominal or pelvic cancer in the previous months or years. Baseline demographic data were collected including age, sex, diagnosis, pain location, characteristics and severity, physical findings and investigations. Appropriate further investigations were carried out in an attempt to establish the diagnosis and appropriate treatment. Follow-up contact determined the mortality and its timing in relation to cancer diagnosis and pain clinic referral.

\section{RESULTS}

The 86 subjects comprised 27 men and 59 women. In the cancer group, there were 22 men and 53 women ranging in age from 32 to 76 years (Table 1 ). Thirty-nine of the 53 women $(74 \%$ ) had previously treated carcinoma of the cervix, and $60 \%$ of the entire group had been previously treated for malignant pelvic disease. Forty-seven patients in the cancer group (63\%) had their disease treatment within the preceding three years (Table 2 ). The patients were referred to the pain clinic with the primary problem of pain in the sites listed in Table 3, and most had a complaint of leg pain. The pain pattern was consistent with fifth lumbar or first sacral nerve root involvement or referred pain from the spine (5). Neurological physical signs were demonstrated in the lower extremities in 38 individuals (44\%), and motor signs were more common than sensory changes. Fifty-six per cent (48 individuals) had no such findings but did manifest a warm, dry foot due to sympathetic deafferentation as the only sign of disease. The primary cancers are shown in Table 4. In the nonmalignant group, four had had surgical sympathectomies, two had spinal fusions and one had controlled diabetes mellitus; in four patients, an adequate explanation was not established for the hot foot. The prognosis was poor in the malignant group. Most had the onset of pain within two years of cancer diagnosis. The median survival for underlying malignancy in this group indicated that 46 of 57 patients $(81 \%)$ followed succumbed within one year.

\section{DISCUSSION}

Interruption of the cervical sympathetic pathway caused by invasion of tumours arising in the lung apex has been well recognized since the description by Henry Pancoast in 1932 (4). As the cancer invades upwards it encounters the sympathetic efferents exiting the lower plexus via the first thoracic nerve root and trunk. Although Pancoast originally described ipsilateral Horner's syndrome (ptosis, miosis, loss of facial sweating) from sympathetic interruption to the face, he did not mention the warmer dry hand due to sympathetic denervation of the arm. All these signs are due to lower brachial plexus involvement and interruption of the sympathetic outflow of the first thoracic nerve. This results early on in an ipsilateral warm, dry hand, and may later be associated with other symptoms and signs of other inferior brachial plexus involvement such as pain, tingling and numbness down the medial arm and ulnar two fingers, and weakness and atrophy of the hand muscles. Less well recognized is that an analogous sign of a warm, dry foot due to sympathetic interruption occurs in the lower extremity from lumbosacral plexus involvement with retroperitoneal tumours 
TABLE 1

The hot foot sign: Retroperitoneal disease according to age $(n=86)$

\begin{tabular}{lccc}
\hline Age, years & Malignant $(n=75)$ & Nonmalignant $(n=11)$ & Total $(n=86)$ \\
\hline $31-40$ & 9 & 3 & 12 \\
$41-50$ & 23 & - & 23 \\
$51-60$ & 19 & 4 & 23 \\
$61-70$ & 19 & 3 & 22 \\
$71+$ & 5 & 1 & 6 \\
\hline
\end{tabular}

Data presented as $n$

TABLE 2

The hot foot syndrome: Interval from first treatment to pain onset in the cancer group $(n=75)$

\begin{tabular}{lc}
\hline Interval & $\mathbf{n}$ \\
\hline $1-12$ months & 25 \\
$13-24$ months & 11 \\
$25-36$ months & 11 \\
$37-48$ months & 8 \\
$49-60$ months & 7 \\
>60 months & 10 \\
Not known & 3 \\
Total & 75 \\
\hline
\end{tabular}

TABLE 3

The hot foot syndrome: Sites of pain $(n=86)$

\begin{tabular}{lc}
\hline Site(s) & $\mathbf{n}$ \\
\hline Lateral, posterior, upper and/or lower leg & 66 \\
Low back, sacroiliac & 10 \\
Ankle, foot & 6 \\
Chest & 3 \\
Perineum & 1 \\
Total & 86 \\
\hline
\end{tabular}

and other lesions. At the time of this study, local recurrence of cancer of the cervix was the most common cause of referral to the Smythe Pain Clinic for intractable pain due to cancer and is the most common cause of the hot foot sign in the present series. It is this physical finding that is reported in the present article and as justifiably as Pancoast's name has been attached to his syndrome, it would be appropriate to attach Dr Evans' name to this as Evans' sign or syndrome.

Primary or metastatic neoplastic disease in the retroperitoneal space may displace or invade nerves and other tissues and refer pain remotely from the tissue of origin. In this circumstance, a patient with a history of previously treated cancer of, for example, the cervix or rectum may begin to complain of pain in a lower limb. The pain sites described are either referred pain from the spine or nerve root (radicular) pain (5). The earliest sign accompanying this pain may be a warm, dry foot due to sympathetic deafferentation by the tumour, and this may occur in the absence of other physical signs $(56 \%$ in the present series) and help to establish the diagnosis and to direct further treatment. A thermogram can substantiate this temperature difference (Figure 2). Untreated, the natural history is progression to weakness of the foot, loss of the ankle reflex, sensory loss and increasing edema from lymphatic obstruction. In those days, venography (Figure 3) or intravenous pyelography were commonly used, but an early (1978) CT scan is shown in Figure 4.

The importance of this original observation by Dr Evans is that a warm, dry foot may be the only sign when pain heralds recurrence of a retroperitoneal cancer, or it may be the only sign of a primary undiagnosed retroperitoneal process. If a retroperitoneal process is suspected and initial examination is negative, uncovering the feet and removing the bed clothes from a bedridden patinet for a few minutes results in
TABLE 4

The hot foot syndrome and primary tumour

\begin{tabular}{lc}
\hline Site & $\mathbf{n}$ \\
\hline Pelvic & 39 \\
Cervix & 3 \\
Bladder & 2 \\
Prostate & 2 \\
Rectum & 1 \\
Ovary & \\
Abdomen & \\
Colon & 3 \\
Kidney & 6 \\
Other & 15 \\
Double primaries & 4 \\
Total & 75 \\
\hline
\end{tabular}



Figure 2) Thermography in a case of the hot foot syndrome substantiating a warmer right foot (arrow)

cooling of the normal, nonpainful foot and an obvious contrast in temperature and dryness occurs. The mechanism of the warmth is vasodilation and the dryness is caused by loss of perspiration, both due to interruption of the sympathetic nervous system in the retroperitoneal space. The prognosis is generally poor with malignant disease in this location without treatment, and treatment is usually palliative. Perhaps the outlook could be improved with earlier diagnosis and recognition based on the hot foot sign.

Another purpose of the present article is a meditation on 'the old way' of taking a detailed history of the patient narrative and a complete physical examination. It is probable that it is only in this way that Dr Evans came upon this physical sign, and it will not be found unless suspected and sought. It is likely that this type of assessment was much more prevalent, in part because it was more necessary; in the era before imaging with CT and MRI, investigations were more invasive and included lymphography, venography (Figure 3) and intravenous pyelography. There remains merit in this clinical approach. Many patients state that their physician does not make eye contact, mostly looks at the computer screen while typing vigorously, and that they feel that this impairs meaningful interaction. They also frequently comment on the brevity of both the history and physical examinations that have been performed to date. One physician working in an academic pain clinic and treating chronic pain with opioids confided that a physical examination was not performed because it had been done before by previous physicians.

A detailed narrative and a hands-on, thorough physical examination should be part of the therapeutic process. Making rounds with Ray was similar to watching a magician pulling rabbits out of a hat, as he 


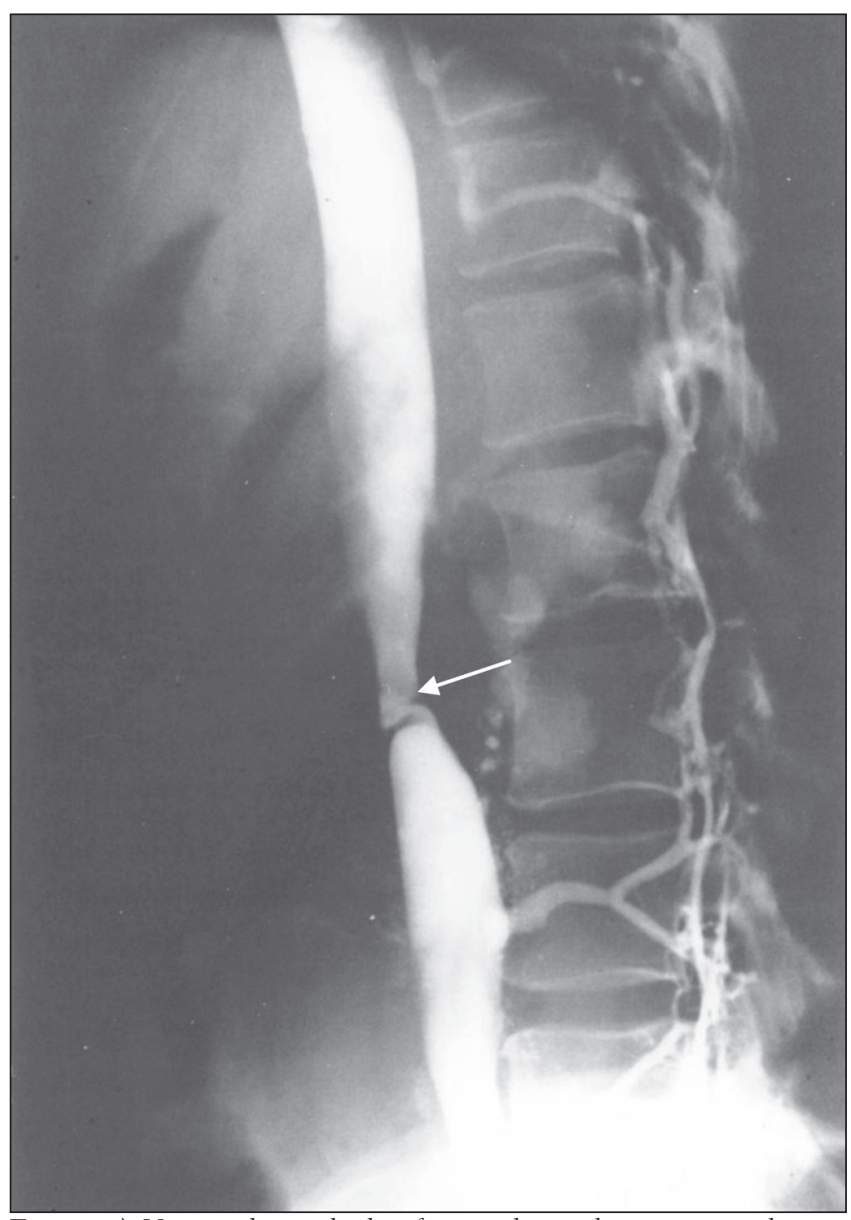

Figure 3) Venography in the hot foot syndrome due to cancer showing deviation of the inferior vena cava due to recurrent tumour (arrow)

implemented the time-honoured approach of inspection, palpation, percussion and auscultation and applied this to searching for recurrent malignant disease $(6,7)$. I have seen him pick up many other physical signs missed by others because of this. Inspection would begin when the patient entered the consulting room, possibly revealing the diagnostic gait of a dropped foot or nonspecific limp that may indicate nerve root involvement, hip disease or retroperitoneal disease. Light palpation of the skin, by skin stroking with cotton or light traction between thumb and forefinger, sought the allodynia or hyperesthesia of neuropathic pain. Often one of the first things he did with a supine patient was to lightly touch the plantar and dorsal surfaces of the feet with his fingertips to test for the hot foot sign of a temperature and dryness difference. Palpation of deeper tissues involved contracting the muscles of the abdominal wall, by the patient raising the head against resistance and/or the lower extremities off the bed to contract the abdominal muscles, to detect tenderness there (Carnett's manoeuvre [6]). Skeletal muscle palpation was routine and sought the tender points of fibromyalgia and trigger zones of myofascial pain. Deep palpation of the relaxed abdomen sought deeper tenderness, masses and enlarged organs within the abdomen. He probed the mouth with a gloved finger to check for recurrent head and neck cancers. Internal examinations were conducted when appropriate. Shoulders, hips and other joints were put through a full range of movement. Sciatica was sought. He would use percussion, with a reflex hammer, to tap over bony areas such as the vertebral spines,

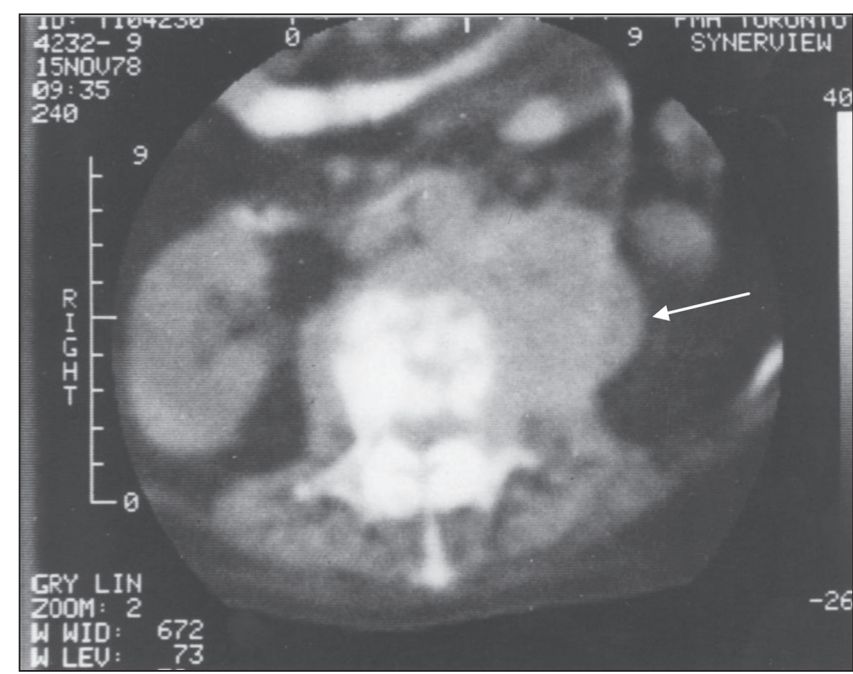

Figure 4) An early, first-generation computed tomography scan (1978) showing a paravertebral tumour in the retroperitoneal space (arrow) in a patient with the hot foot syndrome

ribs, scapulae and pelvis looking for tenderness that may reflect disease metastatic to bone as a cause of pain associated with lung, breast and prostate cancers. Several examples of pelvic pain in female patients due to osteitis pubis were substantiated during my fellowship year by the finding of extreme tenderness to percussion over the symphysis pubis corroborated later by $\mathrm{x}$-ray and bone scan. He was a good neurologist. I can remember many other examples of important information that were obtained, and can still be obtained, in this fashion.

A recent encounter brought Ray to mind regarding a man in intractable pain, depressed, hopeless and bedridden, seen in his rural home. He had been diagnosed as having pain due to severe, nonsurgical osteoarthritis and spondylolisthesis of the lumbar area- and was referred to a pain clinic which booked him, sight unseen, for a series of epidural steroid injections. However, on evaluation, he actually had right costovertebral and right upper quadrant abdominal pain radiating into the groin and testicle, much more typical of a renal problem. He had no leg pain or lower limb signs except one. He had a warm, dry right foot (in this case, a CT scan revealed a hydronephrotic right kidney with a large staghorn calculus, the removal of which relieved his symptoms).

DISCLOSURE: The author has no disclosures.

\section{REFERENCES}

1. Watson CPN. In Memoriam: Ramon James Evans (1932-2007). Pain Res Manag 2007;12:244.

2. Brown RC, Maisey DN, Day JL. Unilateral lumbar sympathectomy due to retroperitoneal tumour. Br Med J 1978;1:410.

3. Paterson IC. Hot foot syndrome. Br Med J 1978;1:787.

4. Pancoast HK. Superior pulmonary sulcus tumour. JAMA 99;1932:1391-6.

5. Bogduk N. On the definition and physiology of back pain, referred pain and radicular pain. Pain 2009;147;17-9.

6. Hagen NA. Pain due to cancer: Epidemiology, prevalence, and cancer pain syndromes. In: Fishman SM, Ballantyne JC, Rathmell JP, eds. Bonica's Management of Pain, 4th edn. New York: Lippincott Williams \& Wilkins 2010:537-558.

7. Hershfield NB. The abdominal wall. A frequently overlooked source of abdominal pain. J Clin Gastroenterol 1992;14:199-202. 


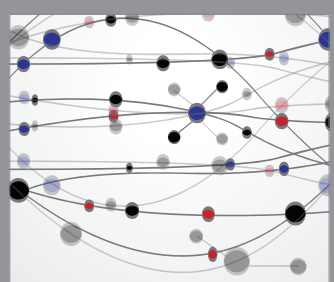

The Scientific World Journal
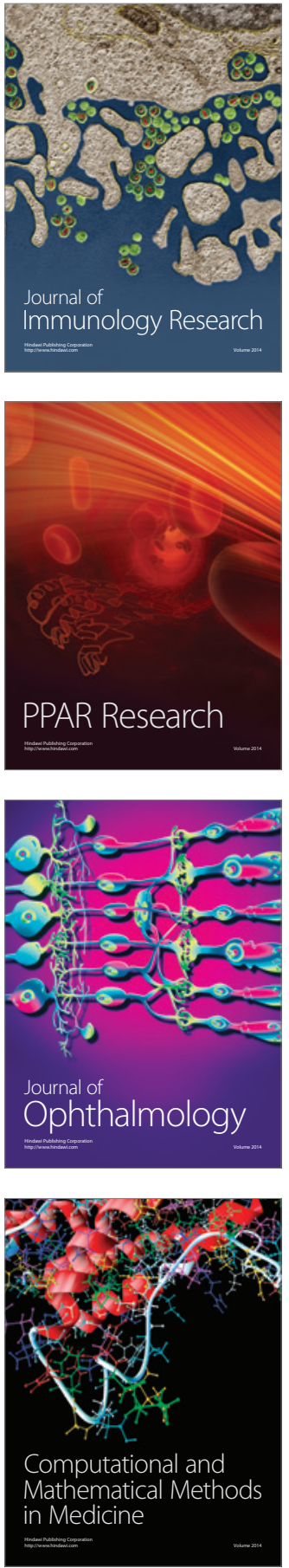

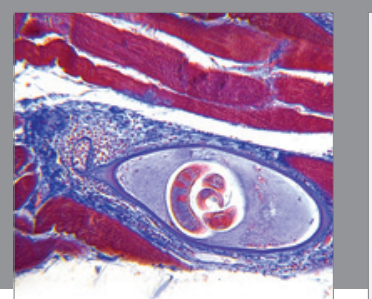

Gastroenterology Research and Practice

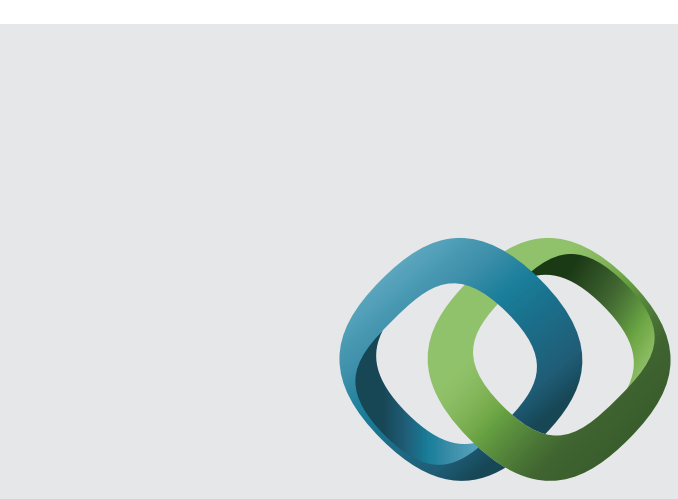

\section{Hindawi}

Submit your manuscripts at

http://www.hindawi.com
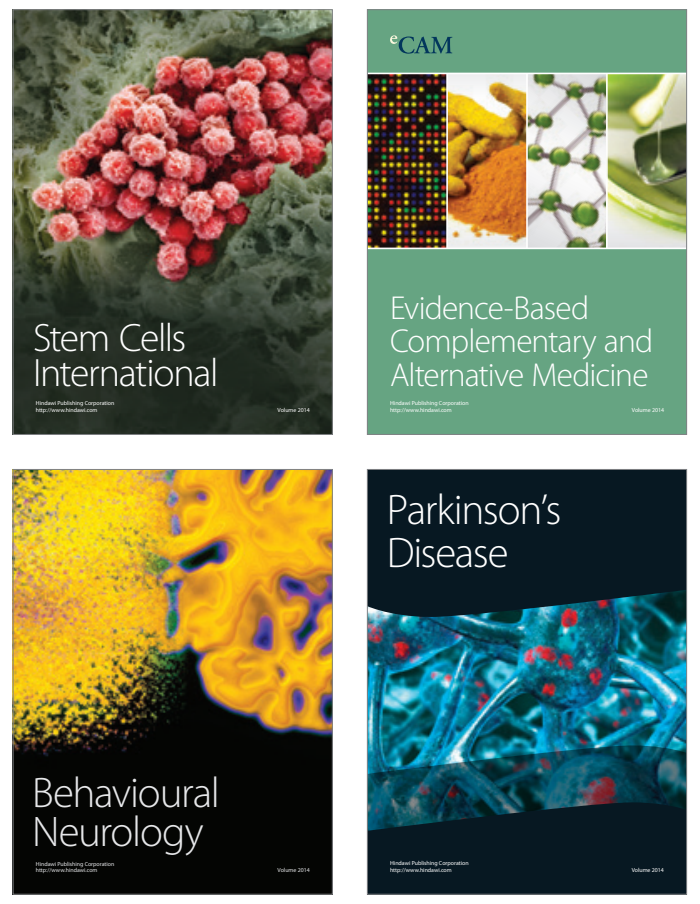
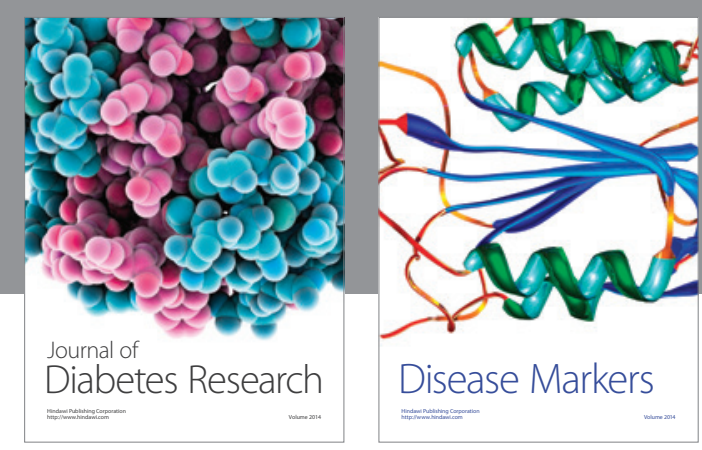

Disease Markers
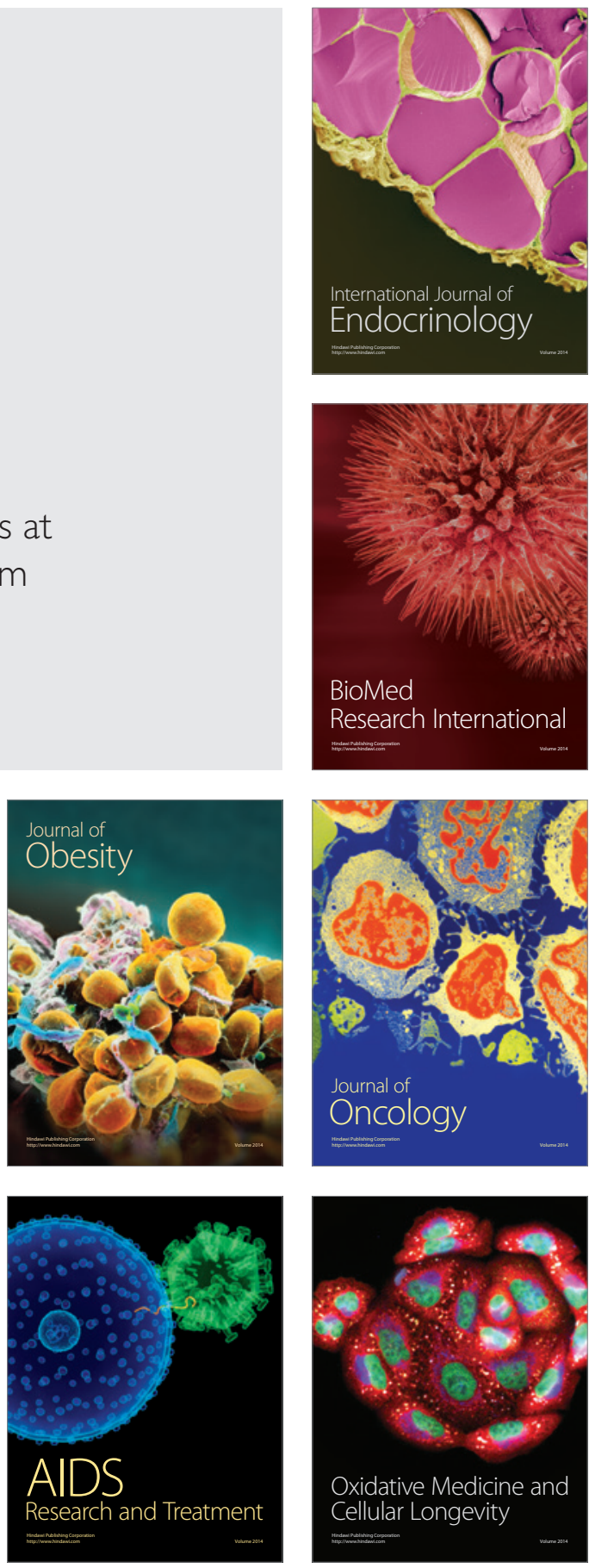